\title{
Evaluation of the mechanisms of sarcopenia in chronic inflammatory disease: protocol for a prospective cohort study
}

Amritpal Dhaliwal 1,2,3 , Felicity R. Williams ${ }^{1,2,3}$, Jonathan I. Quinlan ${ }^{1,3,4}$, Sophie L. Allen ${ }^{3,4}$, Carolyn Greig ${ }^{3,4,5}$, Andrew Filer ${ }^{1,2}$, Karim Raza ${ }^{1,6}$, Subrata Ghosh2,3, Gareth G. Lavery ${ }^{3,5,7}$, Philip N. Newsome, ${ }^{2,3}$, Surabhi Choudhary ${ }^{3}$, Leigh Breen ${ }^{4,5}$, Matthew J. Armstrong ${ }^{2,3}$, Ahmed M. Elsharkawy ${ }^{2,3}$ and Janet M. Lord ${ }^{1,3^{*}}$

\begin{abstract}
Background: Several chronic inflammatory diseases co-exist with and accelerate sarcopenia (reduction in muscle strength, function and mass) and negatively impact on both morbidity and mortality. There is currently limited research on the extent of sarcopenia in such conditions, how to accurately assess it and whether there are generic or disease-specific mechanisms driving sarcopenia. Therefore, this study aims to identify potential mechanisms driving sarcopenia within chronic inflammatory disease via a multi-modal approach; in an attempt to help define potential interventions for future use.
\end{abstract}

Methods: This prospective cohort study will consist of a multi-modal assessment of sarcopenia and its underlying mechanisms. Recruitment will target three chronic inflammatory diseases: chronic liver disease (CLD) $(n=50)$, with a subset of NAFLD ( $n=20)$, inflammatory bowel disease (IBD) $(n=50)$ and rheumatoid arthritis $(R A)(n=50)$ both before and after therapeutic intervention. In addition, 20 age and sex matched healthy individuals will be recruited for comparison. Participants will undergo 4 assessment visits at weeks 0,2,12 and 24. Visits will consist of the following assessments: blood tests, anthropometrics, functional assessment, quadriceps muscle imaging, actigraphy, quality of life questionnaires, food diary collection and muscle biopsy of the vastus lateralis (at weeks 2 and 24 only). In addition, stool and urine samples will be collected for future microbiome and metabolomics analysis.

Discussion: This is the first study to use a multi-modal assessment model to phenotype sarcopenia in these chronic inflammatory diseases. We hope to identify generic as well as disease-specific mechanisms driving sarcopenia. We appreciate that these cohorts do require separate standards of care treatments which limit comparison between groups.

Ethics and dissemination: The study is approved by the Health Research Authority - West Midlands Solihull Research Ethics Service Committee Authority (REC reference: 18/WM/0167). Recruitment commenced in January 2019 and will continue until July 2021. The study was halted in March 2020 and again in January 2021 with the COVID-19 pandemic. The findings will be disseminated through peer-reviewed publications and conference presentations. All data will be stored on a secure server.

Trial registration: ClinicalTrials.gov Identifier: NCT04734496

*Correspondence: j.m.lord@bham.ac.uk

1 Institute of Inflammation and Ageing, University of Birmingham, Birmingham B15 2TT, UK

Full list of author information is available at the end of the article original author(s) and the source, provide a link to the Creative Commons licence, and indicate if changes were made. The images or other third party material in this article are included in the article's Creative Commons licence, unless indicated otherwise in a credit line to the material. If material is not included in the article's Creative Commons licence and your intended use is not permitted by statutory regulation or exceeds the permitted use, you will need to obtain permission directly from the copyright holder. To view a copy of this licence, visit http://creativecommons.org/licenses/by/4.0/. The Creative Commons Public Domain Dedication waiver (http://creativeco mmons.org/publicdomain/zero/1.0/) applies to the data made available in this article, unless otherwise stated in a credit line to the data. 
Keywords: Sarcopenia, Chronic liver disease, Inflammatory bowel disease, Inflammatory arthritis

\section{Background}

In many chronic inflammatory diseases, including rheumatoid arthritis (RA), Inflammatory Bowel Disease (IBD) and chronic liver disease (CLD) incorporating cirrhosis, loss of muscle strength, mass and physical performance (sarcopenia) is a hallmark of advanced disease, contributing to poor patient quality of life, a reduced response to challenges such as surgery or infection, and higher mortality [1]. The current working definition of sarcopenia by the European Working Group on Sarcopenia in Older People (EWGSOP) focuses on low muscle strength and either low muscle quantity or quality with poor physical performance as an indicator of severity $[1,2]$. The extent of sarcopenia and the factors driving it in chronic inflammatory conditions remain poorly defined, limiting strategic or personalised therapeutic intervention.

Muscle mass is determined by the balance of protein synthesis and degradation. Anabolic signals deriving from nutrients (amino acids), physical activity and hormones such as IGF-1 and testosterone, mediate their effects through downstream targets including AKT and mTOR [3]. Catabolic signals which induce protein breakdown through induction of atrogenes such as MAFbx and MURF1, include inflammation, physical inactivity, cortisol generated in muscle via the activation of $11 \beta$ HSD1 and the hormone myostatin which inhibits myoblast differentiation into mature muscle fibres and blocks AKT signalling [4-7]. The relative contribution of these mechanisms to sarcopenia in chronic inflammatory disease remains partially understood and is a major focus of this study.

\section{Chronic liver disease}

A significant proportion of patients with CLD have a degree of malnutrition and this is closely associated with sarcopenia $[8,9]$. Muscle wasting within CLD can be due to several factors including altered metabolism and inactivity. Protein-energy malnutrition is very common in patients with liver cirrhosis (estimated at 65-90\%) [10]. Mechanisms reducing protein synthesis and enhancing degradation such as accelerated starvation where glycogen depletion occurs, insulin resistance and hyperammonaemia predominate in CLD $[10,11]$. It is becoming increasingly clear that the degree of sarcopenia is directly related to outcomes in patients with liver disease. In a recent study of 130 patients with cirrhosis, survival at 5 years was $50 \%$ in those with sarcopenia at baseline, compared to $80 \%$ without sarcopenia at baseline [12]. In a study of 669 cirrhotic patients assessed for transplantation in Canada and the USA, sarcopenia was present in
$45 \%$ of the patients and they had a median survival of 20 months compared to 95 months for those without sarcopenia [13].

In liver disease, sarcopenia may be hidden by either oedema masking muscle loss, or obesity $[14,15]$. Current prognostic indicators such as the Royal Free Hospital Global Assessment (RFH GA) tool, or scoring systems such as Child-Pugh score and Model for End Stage Liver Disease (MELD) [16] score based on anthropometry/nutritional assessment of patients, may thus have reduced sensitivity in the presence of these relatively common confounders. This can underestimate the risk for those with sarcopenia and reduce the validity of assessing and prioritising patients for liver transplant surgery. In addition, since muscle mass is a static reflection of the health of the musculoskeletal system, it is also important to assess dynamic aspects such as strength, power and fatigability.

With the mounting clinical evidence of the negative impact of sarcopenia in cirrhosis, research into the underlying mechanisms is beginning to evolve. A positive anabolic effect has been observed in a small number of cirrhotic patients fed a leucine-rich preparation of amino acids [17] which suggests that cirrhotic patients should respond well to both resistance exercise and nutritional signals. Inflammation can drive muscle degradation, with inflammatory cytokines increasing activity of 11-beta hydroxysteroid dehydrogenase 1 (11ßHSD1) to generate cortisol within the muscle [18] as well as promoting insulin resistance. The profound inflammatory state in cirrhosis may, therefore, be a potential driver of muscle loss.

\section{Inflammatory bowel disease}

Sarcopenia, often included within the spectrum of malnutrition, is present in patients with IBD, including both Crohn's disease (CD) and ulcerative colitis (UC). Malnutrition affects up to $75 \%$ and $62 \%$ of patients with $C D$ and UC, respectively [19]. The current prevalence of sarcopenia in IBD is not fully appreciated; a recent meta-analysis found $52 \%$ of patients with CD and $37 \%$ of patients with UC have sarcopenia (as defined by low muscle mass independently) [20] with a considerable impact on quality of life.

Fatigue is a common symptom associated with IBD [21]. It is multifactorial and not necessarily associated with clinical inflammatory disease activity. Approximately $50 \%$ of patients with IBD report fatigue at the time of diagnosis [22] which can present as diminished physical activity and isokinetic muscle strength. Sarcopenia 
plays a role in impacting on other aspects of quality of life including a reduction in mobility, usual activities and pain/discomfort score compared with healthy controls [23]. The prevalence and clinical impact of sarcopenia in $\mathrm{CD}$ is poorly understood [24]. However, there are several studies that identify the negative impact of sarcopenia on post-surgical outcomes in patients with IBD, for example, increased post-operative complications. Sarcopenia can also be an independent predictor of the need for bowel resection among IBD patients [25]. There is emerging evidence of increasing obesity in patients with IBD, therefore sarcopenic obesity will likely further materialise within this cohort [20].

In relation to drivers of sarcopenia, impaired activation of muscle synthesis pathways such as the IGF1-Akt pathway may be responsible [26]. The reduction in signalling through this pathway is known to be important in the anabolic resistance of age-related sarcopenia but has not been extensively studied in IBD. A key role for inflammation as a driver of muscle wasting has been suggested by a small study which showed sarcopenia was reduced by anti-TNF $\alpha$ monoclonal antibody therapy [27].

\section{Rheumatoid arthritis}

Muscle atrophy develops in two-thirds of RA patients, leading to debilitating rheumatoid cachexia which incorporates sarcopenia, shortened working life and poor quality of life [28]. As similarly reported in IBD cohorts, fatigue is a frequently reported symptom in those with RA [29]. The heightened inflammatory status of RA patients has been linked to an increase in whole-body protein breakdown $[30,31]$. 11ßHSD1 has been shown to be elevated in muscle from patients with $\mathrm{RA}$, this may be a protective response to heightened inflammation as studies with 11ßHSD1 knockout mice lacking this glucocorticoid generating enzyme developed more severe myopathy [32]. Furthermore, anti-TNF $\alpha$ therapy does not reverse sarcopenia, despite control of systemic inflammation, suggesting that other mechanisms are driving sarcopenia in RA [33]. The current most effective treatment to protect against sarcopenia and improve physical function in RA patients is exercise training [34]. It has been demonstrated that patients with RA are relatively sedentary with the majority of their physical activity remaining low intensity [35], however low-level physical activity can stimulate reductions in cardiovascular risk, insulin resistance and mortality [36]. In particular, a recent RCT implementing a supervised progressive resistance training in patients with RA was proven to increase muscle mass with improved function [37].

The aim of this study is therefore to determine the extent of sarcopenia in three chronic inflammatory diseases, CLD, IBD and RA, and to identify the processes, both molecular and lifestyle, contributing to sarcopenia in each disease, in order to identify common and disease-specific mechanisms. This will provide the evidence base for future studies testing interventions to reduce sarcopenia in each of these diseases.

\section{Methods \\ Study overview}

The proposed study is a single centre, longitudinal observational, prospective study of a cohort of patients with sarcopenia associated with chronic inflammatory disease, to identify generic and disease-specific mechanisms that potentially drive sarcopenia.

Patients recruited to the study will undergo several assessments (anthropometric, functional, serological, radiological, lifestyle and health-related quality of life evaluation) to assess their sarcopenia status and provide muscle biopsies on two occasions to allow further analyses including protein turnover, mitochondrial and satellite cell function, RNA sequencing, to be undertaken. Patients will be assessed at four defined time points: baseline, 2 weeks, 12 weeks and 24-week time points to allow analysis pre- and post-biologic therapy in the IBD and RA cohorts. Some of the CLD participants will undergo a liver transplant during their participation allowing a pre- and post-transplant comparison. Patients will be recruited from the University Hospitals Birmingham Foundation Trust, Birmingham, UK. Patients will continue with their standard of care management as determined by their regular specialty team. Age and sex matched healthy controls will undergo the same assessments and provide a muscle biopsy at a single study visit. They will comprise of people without sarcopenia or any significant comorbidities, with a regular level of activity (ie those without a high level of exercise/performance or not sedentary).

\section{Study aims}

The aims of this study are:

1. To assess the extent of sarcopenia in our three target cohorts using several methods to assess muscle mass, physical performance and strength.

2. To identify potential mechanisms of sarcopenia in each disease through a multi-modal assessment process.

3. To observe any longitudinal changes in each cohort over a 6-month period. 


\section{Study design}

\section{Patient selection and sample}

A target of fifty patients (over the age of 18 years) will be selected from:

- Patients with CLD, predominantly liver cirrhosis or end-stage liver disease (ESLD)) who are being assessed for liver transplantation (LT). A further twenty patients with non-alcoholic related fatty liver disease (NAFLD), confirmed by transient elastography $+/$ - liver biopsy, with significant fibrosis (Kleiner fibrosis stages F2-F4) and without ESLD will also be identified and recruited for comparison.

- Patients with active IBD who are undergoing medical management only and are due to commence a new biologic treatment.

- Patients with active rheumatoid arthritis (RA) who are commencing a new biologic treatment.

We will also recruit an age-sex matched sample of twenty healthy individuals as a control cohort for comparison.

This is an observational prospective cohort study with deep phenotyping (experimental) of each patient group to determine the mechanisms underlying sarcopenia in each cohort, therefore a sample size calculation was not applicable. However, we calculated that 50 patients per disease group is sufficient for a Spearman correlation of $\geq 0.3$ to reach statistical significance. Recruitment targets are also based on feasibility within the time frame of the study and based on the planned statistical analysis, described below.

\section{Standard of care treatment}

CLD; Patients with ESLD on a transplant waiting list undergo prehabilitation (the process of enhancing functional capacity to enable the patient to withstand a forthcoming stressor [38]). This includes physical activity and nutritional optimisation $[9,39,40]$.

IBD; The British Society of Gastroenterology have clear guidelines stating when treatment with a biologic therapy is indicated and are used for moderate disease $+/$ - failure of second-line treatment in CD and UC [41].

RA: The National Institute for Health and Care Excellence (NICE) have devised a formal guidance for drug treatment in rheumatoid arthritis. This includes those with severe disease (Disease activity score (DAS) $>5.1$ ) and failure of response with combination DMARD therapy [42-44].

\section{Eligibility criteria}

Eligible patients will be screened via the following criteria (Table 1). CLD patients will be selected from those who undergo assessment for liver transplantation. A Non-alcoholic fatty liver disease (NAFLD) subset will be screened and recruited from the NAFLD clinic. For IBD and RA, all patients commencing a new biologic treatment (via biologic clinic screening or biologic registry screening) will be screened prior to therapy commencement.

\section{Participant recruitment}

Participants will be recruited from University Hospitals Birmingham, Birmingham, UK.

CLD cohort All patients who attend the outpatient LT assessment clinic will be screened on the eligibility criteria. Patients with any degree of muscle wasting or functional decline will be invited to take part in the study. For the NAFLD cohort, we will screen all patients attending NAFLD clinic against the eligibility criteria.

$I B D$ and RA cohorts For RA patients, the biologics registry will be screened, and eligible participants directed towards the research team. For IBD patients, potential participants will be identified from the nurse-led biologic clinic attended by those commencing a new biologic. A selection of patients may be identified by the IBD multidisciplinary meetings during discussions of standards of care.

Invitations to participate in the study will occur via face to face interaction during clinic and patient information sheets (PIS) distribution through post or email to eligible patients by the clinical research teams. We will then contact the patient up to 4 weeks after they have received the PIS to discuss their potential participation. The patient will be free to refuse to take part or withdraw from the study at any time and this decision will not affect their care.

Control cohort Poster advertising recruitment will be disseminated across the University of Birmingham, targeting staff and students. All participants who volunteer will then be screened for eligibility.

\section{Study schedule and method}

This study entails four visits spanning a 24-week period. Figure 1 provides an overview of the duration and assessment carried out for each visit. Some of the visits may occur outside of the selected time frames for each visit, for example, to accommodate LT, unexpected illness 
Table 1 Eligibility criteria for participants with chronic liver disease, rheumatoid arthritis or inflammatory bowel disease

\begin{tabular}{|c|c|c|}
\hline & Inclusion criteria & Exclusion criteria \\
\hline CLD, IBD and RA & $\begin{array}{l}\text { 1. A formal confirmed diagnosis of their underlying chronic inflammatory condition: } \\
\text { IBD cohort patients will have endoscopic or radiological evidence. } \\
\text { Some of the CLD cohorts will have had a liver biopsy, serological and radiological confirma- } \\
\text { tion will be sufficient. } \\
\text { a. RA cohort, clinical, serological and radiological confirmation will be sufficient. } \\
\text { b. Biologic therapy naïve on recruitment or commencing a new biologic if in the IBD or IA } \\
\text { cohort. } \\
\text { 2. Adults aged } \geq 18 \text { years } \\
\text { 3. Able to confirm written consent to the study } \\
\text { 4. Biologic therapy naïve on recruitment or commencing a new biologic if in the IBD or RA } \\
\text { cohort } \\
\text { Pre-existing or current use of immunosuppressant agents or Disease Modifying Antirheumatic } \\
\text { Drugs (DMARDs) are acceptable in all cohorts. } \\
\text { 5. Meeting ACR (American College of Rheumatology)/EULAR (European League Against } \\
\text { Rheumatism) } 2010 \text { or ACR } 1987 \text { Criteria for rheumatoid arthritis and starting DMARD } \\
\text { therapy. } \\
\text { 6. Meeting criteria of an inflammatory arthritis as per the American College of Rheumatol- } \\
\text { ogy } \\
\text { 7. Meeting criteria of liver cirrhosis including all Child Pugh scores from A-C as per British } \\
\text { Association for the Study of the Liver guidance. } \\
\text { 8. Meeting criteria for IBD as per the British Society of Gastroenterology guidance. } \\
\text { 9. For muscle biopsy sampling (does not preclude patients from participating if they do not } \\
\text { meet the below criteria) } \\
\text { INR } \leq 1.6 \\
\text { Platelet count > } 30\end{array}$ & $\begin{array}{l}\text { 1. Refusal or lack capacity to give } \\
\text { informed consent. } \\
\text { 2. Currently enrolled in an interven- } \\
\text { tional trial with active treatment for } \\
\text { their chronic disease condition. } \\
\text { 3. Previously undergone LT or biliary } \\
\text { intervention in the CLD cohort. } \\
\text { 4. Underlying or active cancer. } \\
\text { 5. Biliary intervention if CLD } \\
\text { 6. For Muscle biopsies only (able to } \\
\text { continue in study): } \\
\text { a. Obvious injury to both thighs. } \\
\text { b. Active bleeding of site, pre- } \\
\text { procedure, } \\
\text { c. Abnormal observation param- } \\
\text { eters. } \\
\text { d. Acute illness. } \\
\text { e. INR > 1.6. } \\
\text { f. Platelet count < } 30 \text {. } \\
\text { g. Anticoagulation which cannot } \\
\text { be paused due to increased risk to } \\
\text { pre-existing comorbidity. } \\
\text { 7. For undergoing an MRI } \\
\text { a. Pacemaker. } \\
\text { b. Metal work inserted that is not } \\
\text { MRI compatible or further informa- } \\
\text { tion cannot be obtained. }\end{array}$ \\
\hline Healthy controls & $\begin{array}{l}\text { 1. Adults aged } \geq 18 \text { years. } \\
\text { 2. Able to confirm written consent to the study. } \\
\text { 3. No co-existing chronic inflammatory condition, cancer or significant premorbid disease } \\
\text { pathology. } \\
\text { 4. No suspicion or evidence of sarcopenia. } \\
\text { 5. No previous transplantation. }\end{array}$ & $\begin{array}{l}\text { 1. Refusal or lack capacity to give } \\
\text { informed consent. } \\
\text { 2. Pregnancy. } \\
\text { 3. Any recent acute illness or surgery } \\
\text { requiring significant treatment or } \\
\text { hospitalisation (within the last } 12 \\
\text { weeks). } \\
\text { 4. Any systemic corticosteroid use or } \\
\text { replacement. } \\
\text { 5. For muscle biopsies only: } \\
\text { a. Obvious injury to both thighs. } \\
\text { b. Active bleeding of site, pre- } \\
\text { procedure. } \\
\text { c. Abnormal observation param- } \\
\text { eters. } \\
\text { d. Acute illness. } \\
\text { e. INR }>1.6 \text {. } \\
\text { f. Platelet count < } 30 \text {. } \\
\text { g. Anticoagulation which cannot } \\
\text { be paused due to increased risk to } \\
\text { pre-existing comorbidity. }\end{array}$ \\
\hline
\end{tabular}

or events that can occur during their participation. If patients have been admitted during the timing of a visit, we will seek permission from the team overseeing their care and the patient, for participation if clinically safe and feasible to do so.

\section{Experimental variables}

The primary experimental variables for this study are:

1. To identify the best non-invasive assessment parameters to evaluate sarcopenia in CLD, IBD and RA and acquire data for the degree of sarcopenia in each disease cohort (muscle area, strength, functional state and activity indices).

2. To identify any longitudinal change in measures as determined by change in muscle mass, strength and function over a 6-month period, in concordance with their clinical status and treatment.

The disease-specific secondary experimental variables related to mechanisms potentially driving sarcopenia are highlighted in Table 2. 

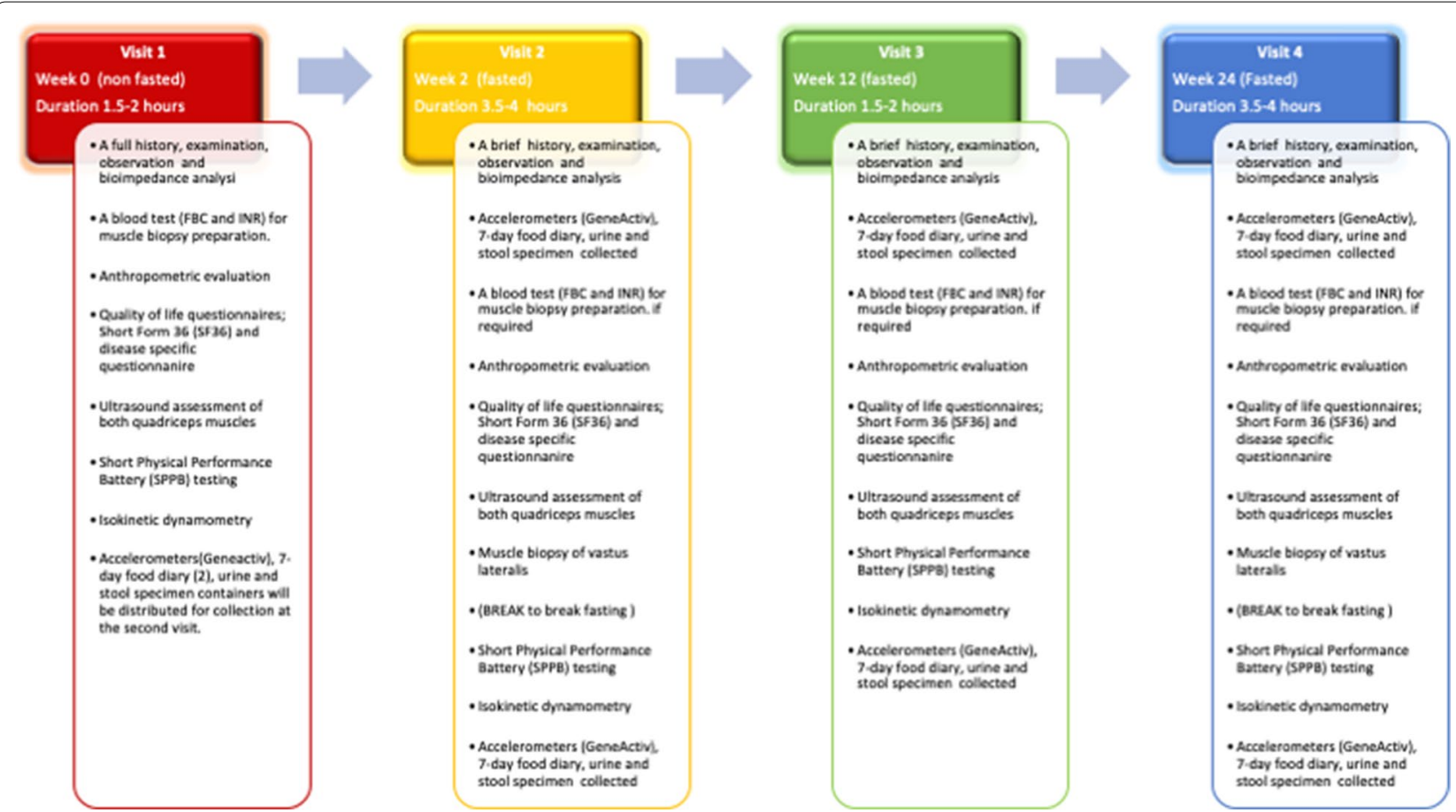

Fig. 1 Flow chart to summarise each visit and time point of the study and the assessments performed

\section{Assessment modalities}

We will carry out the following assessments as described below.

Full clinical history and examination: including a full set of routine observations.

Assessment of blood samples: $\mathrm{C}$ reactive protein, ESR, baseline renal function, liver function, full blood count, clotting function, vitamin $\mathrm{D}$, ferritin, folate, vitamin B12, thyroid function, lipids, and trace elements (zinc, selenium and vitamin A) [46]; cytokine and adipokine panel (interleukin (IL)IL1 $\beta$, IL4, IL6, IL8, IL10, IL12, IL13, IL16, IL17, IL23, IL33, ILIRA, tumour necrosis factor alpha (TNF $\alpha)$, leptin, ghrelin, adiponectin) will be measured by Luminex [47]; serum cortisol, cortisone, dehydroepiandrosterone (DHEA), dehydroepiandrosterone sulphate (DHEAS) and 3-methyl histidine (assessing skeletal muscle catabolism) by mass spectrometry [48, 49]; peripheral blood mononuclear cells (PBMCs) will be collected and stored at $-80{ }^{\circ} \mathrm{C}$ for future analysis of the degree of immune ageing.

Urine and stool sampling: A 30-ml urine and 30-g stool sample from the preceding $36 \mathrm{~h}$ will be collected and stored for metabolomic, inflammatory and microbiome analysis (dependent on further funding).
Anthropometric assessment: Age, weight, height, waist and hip circumference, and body mass index will be measured. Bioelectrical impedance analysis will be performed to estimate percentage body fat and fat-free mass [1]. Hand grip strength (HGS), mid-arm muscle circumference (MAMC) and triceps skinfold thickness (TSF) will be determined.

Functional assessment: This will include accelerometry, Short Physical Performance Battery (SPPB) testing and isokinetic dynamometry.

Accelerometry: Physical activity, sedentary time and sleep duration and quality will be evaluated using a GeneActiv accelerometer wristwatch, worn for 14 days prior to visits 2,3 , and 4 .

SPPB: This measure is validated to predict mortality through the assessment of gait speed (time to walk 4 metres), standing balance and repeated chair stands (sit to stand test). This is scored out of a maximum of 12 points, with a maximum of 4 in each domain $[50,51]$.

Isokinetic dynamometry: This measures strength and power via knee extension. Maximal muscle strength will be measured as the peak torque [52]. Muscle imaging: Ultrasonographic (US) imaging of the quadriceps will measure muscle size, architecture and quality. Magnetic resonance imaging (MRI) will be used to assess muscle size (cross-sectional area, (ACSA), muscle volume of quadriceps and 


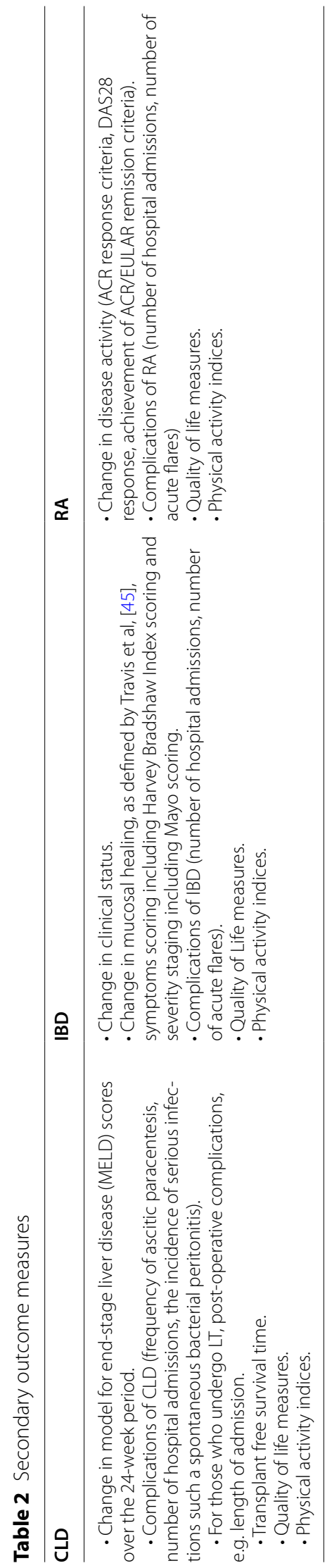


muscle quality (through intramuscular fat measures, myosteatosis and echogenicity of the muscle). All image results will undergo a review by Consultant Musculoskeletal Radiologist.

Muscle tissue evaluation: A biopsy of the vastus lateralis will be performed from the dominant leg at visits 2 and 4 to evaluate muscle fibre structure and fibre phenotyping via immunohistochemistry. Biomolecular analysis of key anabolic and catabolic pathways, including genomic, epigenomic and transcriptomic analysis will be performed to give further understanding of the processes driving sarcopenia.

An urgent blood test will be performed on the day of biopsy, to check clotting and platelet function are within criteria, if one has not already been performed within the preceding two weeks.

Quality of Life (QoL) assessment: This will be measured using two validated questionnaires. All participants will be asked to complete the Short Form-36 (SF-36) health-related QoL questionnaire (Quality Metric Health Outcomes Solutions, Lincoln, USA) [53]. It is a practical, reliable, and validated measure of physical and mental health.

Each cohort will be asked to complete a disease-specific validated tool:

CLD cohort - Chronic Liver Disease Questionnaire (CLDQ): A 29-item tool that evaluates the following domains: fatigue, activity, emotional function, abdominal symptoms, systemic symptoms, and worry [54].

RA cohort - Functional Assessment of Chronic Illness Therapy - Fatigue (FACIT-F) Questionnaire: A 13-item tool that evaluates the following domains: physical, social, emotional and functional wellbeing to measure an individual's level of fatigue during their usual daily activities over the past week [55].

IBD cohort - Inflammatory Bowel Disease - Disability Index (IBD -DI): A 28-item tool that evaluates activity and participation, body structures and environmental factors [21].

Nutritional evaluation will be carried out for the two weeks preceding each interval review, via a 14-day food diary [8]. Diet Plan 7 (Forestfield Software Limited) will be used to calculate the macro and micronutrient intake accordingly.

Table 3 highlights the methods for performing some of the assessments in detail.

\section{Statistical analysis plan}

All quantitative data will be entered into a purposedesigned database and exported for statistical analysis in relevant statistical software. Members of the research team, including a statistician, will conduct the analysis. The analyses that will be performed will include:

1. The extent of sarcopenia in the three target chronic inflammatory diseases using several methods to assess muscle mass, function and strength and compare these data with the EWGSOP criteria.

2. Identification of potential mechanisms of sarcopenia that occur in CLD, IBD and RA achieved through a multi-modal assessment process.

3. Assessment of any longitudinal changes in each cohort over a 6-month period following their standard of care.

4. Assessment of the best non-invasive assessment parameters for evaluation of sarcopenia will be made via analysis of the results of anthropometric, functional, and imaging data, using non-parametric analysis via Spearman correlation. Specifically, we will carry out the following:

- Baseline descriptions of clinical parameters and sarcopenia with proportions demonstrated and median and mean formulated.

- Correlation analysis of measures of sarcopenia and how they relate to disease severity, QoL, etc., will be performed by qualitative measures.

- Comparisons between disease types will be made using non-paired, non-parametric testing.

- Dynamic changes over 6-months (pre and post 6-months of standard of care treatment) will be assessed using paired, parametric and non-parametric testing.

\section{Adverse event management}

An adverse event is defined as any untoward medical occurrence in a subject and does not necessarily have a causal relationship with this study. Potential adverse events would include any side effect or complication post invasive assessment including serological testing and muscle biopsies. Patients will be consented for each individual procedure performed.

Adverse events will be graded according to the Common Terminology Criteria for Adverse Events (CTCAE), the Principal Investigator will be informed immediately, and the appropriate action will be taken, with the event recorded in the CRF. 
Table 3 Methodology for measurements

\begin{tabular}{|c|c|}
\hline Measurement & Method \\
\hline Hang grip strength & $\begin{array}{l}\text { Three trials with a rest of } 30 \mathrm{~s} \text { between the tests will be performed for each hand, with a handheld Takei digital dynamometer } \\
\text { and patients will be encouraged to exert their maximal grip strength }[1,56] \text {. An average value will be calculated. }\end{array}$ \\
\hline MAMC & $\begin{array}{l}\text { This is the midpoint between the lateral edge of the acromion and olecranon process of the radius, on the mid line of the } \\
\text { posterior surface of the dominant arm; it is measured with the arm in a supine position, flexed at the elbow with the forearm } \\
\text { rotated against the body at } 90 \text { degrees, and the hand resting against the torso. Once the midpoint is marked, the arm returns } \\
\text { to a supine position with the hand against the thigh. The MAMC is measured around the midpoint mark ensuring the meas- } \\
\text { uring tape is even against the skin (without being taut). This will be repeated twice, and the mean result calculated. }\end{array}$ \\
\hline TSF & $\begin{array}{l}\text { From the midpoint calculated above, a vertical pinch with a Harpenden calliper, parallel to the long axis of the arm, is made } \\
\text { at the landmark in a perpendicular direction. Measurement in millimetres will be taken; it will be repeated twice, and a mean } \\
\text { is calculated [57-59]. }\end{array}$ \\
\hline Isokinetic dynamometry & $\begin{array}{l}\text { This measures strength and power via knee extension. Maximal muscle strength will be measured as the peak torque [52]. } \\
\text { Patients will be seated in an adjustable, straight-backed chair with their hips and their knees flexed at } 90^{\circ} \text {; their pelvis and the } \\
\text { thighs will be secured by a broad strap with their arms crossed in front of their chest. After the instruction and } 2-3 \text { practi- } \\
\text { cal trials, the patient will be asked to extend, then flex the leg with maximal effort, for } 5 \text { repetitions. Both legs will be tested, } \\
\text { unless contraindicated by pain or other symptoms. Unilateral limb tests will be performed on the non-biopsied leg, following } \\
\text { a muscle biopsy }[60,61] \text {. }\end{array}$ \\
\hline US scan & $\begin{array}{l}\text { Patients will lie in a semi-supine position with legs resting flat on a bed. All images will be taken at } 50 \% \text { of femur length } \\
\text { (measured from the greater trochanter to the lateral knee joint space). The maximal anatomical ACSA of human quadriceps is } \\
\text { shown to be at } 50 \% \text { of the femur length [62]. } \\
\text { Two-dimensional B-mode ultrasonography Esoate MyLab Alpha point of care ultrasound, } 4.6 \mathrm{~cm} \text { probe (SL1543, 13-4Mhz } \\
\text { scanning frequency)) will be performed. } \\
\text { Three longitudinal scans will be taken at } 50 \% \text { femur length of the vastus lateralis muscle with the probe aligned to the } \\
\text { fascicles; allowing for quantification of fascicle length and pennation angle. Vastus lateralis muscle thickness (defined as the } \\
\text { perpendicular distance between the superficial and deeper aponeurosis) will be obtained. All variables will be obtained } \\
\text { offline via image J imaging software and will be presented as a mean. } \\
\text { For assessment of all quadricep muscles, two extended field of view ultrasound images will be taken at } 50 \% \text { femur length; } \\
\text { this will allow for the quantification of quadriceps ACSA. Echogenicity can be determined using a computer-assisted grey- } \\
\text { scale analysis offered by ImageJ }[63,64] \text {. }\end{array}$ \\
\hline MRI femur & $\begin{array}{l}\text { Axial and sagittal plane scans of each thigh will be obtained using an MR 3T scanner for higher quality, efficient imaging } \\
\text { capture and 3D reconstruction. A T1 weighted Spin Echo protocol will be used (repetition time 600ms, echo time } 15.2 \mathrm{~ms} \text {, } \\
\text { Field of view } 512 \times 512 \mathrm{~mm} \text {, slice thickness } 10 \mathrm{~mm} \text {, no gap between slices). } \\
\text { Patients will lie supine on a preparation bed for up to } 20 \text { min to allow fluid shift stabilisation. A series of axial plane scans } \\
\text { along the entire length of the quadriceps muscle group and sections at the L3 lumbar spine (L3 lumbar spine to quadriceps } \\
\text { insertion on the tibia) will be collected. } \\
\text { The contours of the quadriceps will be digitalised offline using the Osirix DICOM image analysis software (Pixmeo, Geneva, } \\
\text { Switzerland) and the quadriceps muscle volume will be calculated [65]. 3-dimensional acquisition of both thighs and a Dixon } \\
\text { sequence will be performed for fat analysis. } \\
\text { Quadriceps muscle ACSA will be measured as described in the above. This midpoint of each femur length and the midpoint } \\
\text { of VL (which is where ultrasound CSA measurements are taken from) will be marked with an external marker to ensure this } \\
\text { is identified on MR images for analysis purposes and comparisons with ultrasound measurements. All image results will } \\
\text { undergo a review by Consultant Musculoskeletal Radiologist. }\end{array}$ \\
\hline Muscle biopsy & $\begin{array}{l}\text { The patient will be fasted for } ~ 6 \mathrm{~h} \text { prior to the procedure. The ultrasound performed will identify the correct position to } \\
\text { ensuring the sample is taken from the muscle belly. The non-dominant limb will be used if the dominant limb is not feasible. } \\
\text { A small area of skin overlying the outer thigh will be cleaned with iodine solution. } 5-10 \mathrm{ml} \text { of } 1 \% \text { lignocaine is infiltrated into } \\
\text { the subcutaneous adipose tissue and down to the muscle. After adequate anaesthetic, a small incision is made in the skin } \\
\text { (approximately } 5-7 \mathrm{~mm} \text { in length). A needle is inserted into the muscle and a small amount of muscle is taken using a well- } \\
\text { described technique with a Bergstrom needle. A few passes may be performed. The incision will be closed using 'steri-strips' } \\
\text { and a single suture, if required. A small dressing will then be placed over the biopsy site. Pressure and an ice compress will } \\
\text { be applied to the area for } 10 \text { min by hand. A pressure bandage which will stay on for } 8 \mathrm{~h} \text { to decrease the risk of bruise forma- } \\
\text { tion. Patients will be asked to keep this area dry for at 3-5 days. All patients will receive after care advice and contact if any } \\
\text { problems do arise. }\end{array}$ \\
\hline
\end{tabular}

A serious adverse event (SAE) is an adverse event that fulfils one or more of the following criteria: results in death, is immediately life-threatening, requires prolongation of existing hospitalisation, results in persistent or significant disability or incapacity, or is an important medical condition. The causality of a serious adverse event will be assessed by the investigators and recorded on the SAE form. All SAEs will be notified to the sponsor's Research and Development department via the SAE form in the case report form (CRF). Only those events classified as probable or related will be reported to the Research Ethics committee. 


\section{Data management}

All data for an individual participant will be collected by the PI or their delegated nominees and recorded in the case report form (CRF). Participant identification in the CRF will be through their unique Participant Study Number allocated at the time of consenting for the study. Data will be collected from the time the patient is considered for entry into the study through to completion of the study. All clinical data will be stored as per NHS regulations and held on a protected database. We will require some data which may be patient identifiable from Hospital Episode Statistics; however, these data will then be inputted in a non-identifiable manner under the standardised data collection guidance to ensure confidentiality and security.

Data from the CRF will be entered onto a secure password protected RedCap database held on a passwordprotected area within a University Hospitals Birmingham (UHB) NHS Foundation Trust server. Some research data may also be transferred to the University of Birmingham anonymously for further research purposes. Patients will be consented for this. Due care will be taken to ensure data safety and integrity, and compliance with the Data Protection Act 2018. All essential documentation and trial records will be stored in conformance with the applicable regulatory requirements and access to stored information will be restricted to authorised personnel. Coded research data will be stored for 10 years anonymously under the property of UHB NHS Foundation Trust in keeping with good clinical practice.

\section{Case report forms}

CRFs will include baseline/follow-up medical history and physical examinations, comorbidities and concomitant medications. Additional information incorporated in the electronic database will include basic clotting and full blood count, observations, anthropometric data, bioimpedance analysis, completion of ultrasound, MRI, and muscle biopsy (visit 2 and 4 only), recorded for each visit. Other CRFs will include AE reporting.

\section{Patient and public involvement (PPI)}

We designed the study with ongoing participation of specific patient groups. We held an initial forum where we presented the study concept and design to a PPI group and received feedback which was incorporated into our design. All patient information sheets and documentation were reviewed by the Liver and Gastroenterology PPI group and a Rheumatology PPI group (at UHB) independently and modified accordingly. During the study, we have had ongoing input from the participants, some of which has been implemented during their experience.
A summary of the results will be disseminated to all participants at the end of the study following analyses.

\section{Monitoring and quality assurance}

The study will be conducted according to the current guidelines for Good Clinical Practice (GCP). Any deviation, that does not result in harm to the trial subject or significantly affect the scientific value of the study, will be documented in the CRF and appropriate corrective or prescriptive actions taken.

Any serious breaches will be immediately reported to the Principal Investigator who will take whatever immediate action is required to safeguard the wellbeing of the participant. The Chief Investigator will notify the Sponsor immediately and the Ethics committee within 7 days of becoming aware of the serious breach.

\section{Dissemination and publication}

Results will be presented at relevant national and international conferences and submitted for publication in peerreviewed open access journals. Participants will be asked if they would like to be informed of the study results at the time of obtaining consent.

\section{Research governance}

The study will be carried out in accordance with the Declaration of Helsinki, under Good Clinical Practice guidelines. This study is not a Clinical Study of an Investigational Medicinal Product, and thus is not governed by the Medicines for Human Use (Clinical Trials) Regulations 2004.

\section{Discussion}

This is the first observational study to deep phenotype sarcopenia using a multi-modal assessment method of both mass, function and strength and quality of life measures.

\section{Justification of study cohorts}

Chronic inflammation is believed to result in an environment which contributes to sarcopenia, though the exact mechanisms remain unclear and may vary between different diseases. We selected this spectrum of chronic inflammatory diseases as in their extreme, acute presentations, the degree of sarcopenia can be profound. We recognise that the standard of care does vary within these cohorts, with biologic treatment in the RA and IBD cohorts and prehabilitation in the CLD cohort). However these were chosen to represent the spectrum of chronic inflammation. This will allow us to observe the mechanisms and findings across this wide spectrum. The CLD cohort comprise of patients with decompensated liver disease, who are in the end stage of their chronic 
inflammatory insult. In addition, the NAFLD subset represents early stages in a chronic inflammatory process with some of these patients having potential reversible fibrosis and in comparison, to the patients with ESLD, these patients have compensated liver disease. The RA and IBD cohorts will reflect those with a significant degree of disease severity to require treatment with a biologic agent. Whilst we appreciate that we can compare only some of the elements between cohorts, it will highlight possible trajectories of sarcopenia with treatments which may be further investigated.

\section{Challenges in study design}

We have tried to incorporate previously validated measures of sarcopenia to compare to newer evolving assessments. For example, the using of validated L3 lumbar muscle cross-sectional area [50, 66-68], HGS of nondominant limb, SPBB as a measure of functional capacity [69], and comparing these to more novel techniques such as ultrasound analysis of quadriceps muscles [70-72], and functional variables such as isokinetic dynamometry and physical activity [73, 74]. Importantly, segmental sarcopenia can occur in patients, therefore adequate assessment of global function is imperative to determine their degree of sarcopenia, and subsequent treatment and mortality risk especially in those undergoing liver transplantation assessment $[66,68,75]$.

We are also investigating factors that affect sarcopenia such as sleep efficiency and quality $[76,77]$ and hope to correlate this to mass and functional variables. These may be important factors that should be considered to ameliorate sarcopenia.

Covert hepatic encephalopathy is frequent in patients with end-stage liver disease and as a result can affect cognition and is of relevance to this study, namely the ability to consent [78]. Many patients are commenced on rifaximin to treat and manage this. We will tackle this by ensuring an adequate period for the patient to read the PIS, having a family member or friend present during visits, reconfirming consent at each visit and performing full capacity testing on initial review and at each required interval. We will exclude any patients who had severe HE which would impact their ability to consent and consistently and adequately follow instruction and most importantly for their own safety.

\section{Confounding medications}

Most patients with inflammatory disease are treated with a variety of medications. For the purposes of this study, we have allowed those on oral steroids or DMARDs in all cohorts. Additionally, those within the CLD cohort may have their follow up visits post liver transplantation, for which they will be treated with immunosuppression.
Given it is unsafe to pause any of these, and this is an observational study, we are recording these data. We recognise it may compound muscle loss.

\section{Muscle biopsy}

This is the first study to attempt large samples of sequential muscle biopsies in these cohorts. It will allow the collection of safety data, however importantly, it allows comparison and analysis of functional and mass measures with muscle histology.

\section{Safety}

Whilst the main stay of this study is observational, there have only been a few studies which have performed muscle biopsies of the vastus lateralis in patients with significant comorbidities such as liver cirrhosis [79]. We will use a Bergstrom needle which is safe, uses a small incision and therefore has a reduced risk of infection and bleeding. Also, using the vastus lateralis is safer as there are limited motor units, with no major blood vessels or nerves traversing the biopsy site [80]. We will perform an ultrasound of the thigh prior to biopsy as part of the study; however, we will use this to additionally check for the optimum site, the presence of any aberrant vessels, and the depth from skin to muscle, to aid the biopsy procedure. A stringent safety checklist is in place to ensure that every patient is adequately risk assessed including allergies, equipment and personnel present. This includes a pre-biopsy check of their INR and clotting. A cut off of INR $\leq 1.6$ and platelet count $\geq 30$ will be used in concordance with national and local radiology guidance for procedures entailing a similar risk profile [81, 82]. All medications will be checked and any antiplatelet or anticoagulation medications will be noted. A biopsy procedure will not be undertaken in those for whom stopping medication may incur significant risk, e.g. warfarin for atrial fibrillation and increased stroke risk. If feasible, medication will be stopped for a minimum of 3 days in advance, in accord with drug half-life and national guidelines for endoscopic procedures [83].

All patients will have a point of care blood sugar (BM) checked pre biopsy procedure as those with diabetes and liver disease are at risk of hypoglycaemia from fasting. Those on any medications that need to be paused or hypoglycaemic including insulin will be contacted in advance and advised accordingly on adjustment of insulin doses the day prior to and of the biopsy and visit [84].

\section{Future consideration}

At the end of the study, each participant will be invited to attend a focus group to

feedback on their experience of the study. This study will provide baseline data for consideration of a follow-on 
study focusing on intervention to potentially reverse or reduce the progression of sarcopenia in this patient group.

\section{Conclusion}

This is the first study to use a multi-modal assessment model to phenotype sarcopenia in a spectrum of patients with chronic inflammatory disease. By selecting these diverse cohorts we hope to identify the common mechanisms driving sarcopenia whilst appreciating the individual differences that may arise. This unique comparison may highlight differences that need to be considered when assessing and treating sarcopenia across the spectrum of chronic inflammatory disease. We appreciate that these cohorts do require a separate standard of care treatments which limit comparison between groups. The enrolment of participants to the study commenced in January 2019 and is due to complete in July 2021. The full analysis is expected by Q1 2022.

\begin{abstract}
Abbreviations
RA: Rheumatoid arthritis; IBD: Inflammatory bowel disease; CLD: Chronic liver disease; EWGSOP: European Working Group on Sarcopenia in Older People; RFH GA: Royal Free Hospital Global Assessment; MELD: Model for End Stage Liver Disease; UKELD: United Kingdom Model for End Stage Liver Disease; 11ßHSD1: 11-beta hydroxysteroid dehydrogenase 1; CD: Crohn's disease; UC: Ulcerative colitis; HMB: $\beta$-Hydroxy- $\beta$-methylbutyrate; PUFA: Polyunsaturated fatty acids; ESLD: End-stage liver disease; LT: Liver transplantation; IA: Inflammatory arthritis; EULAR: European League Against Rheumatism; NAFLD: Nonalcoholic fatty liver disease; IL: Interleukin; DHEA: Dehydroepiandosterone; DHEA-S: Dehydroepiandosterone sulphate; PBMCs: Peripheral blood mononuclear cells; HGS: Hand grip strength; MAMC: Mid-arm muscle circumference; TSF: Triceps skinfold thickness; SPPB: Short Physical Performance Battery; MRI: Magnetic resonance imaging; ACSA: Cross-sectional area; DEXA: Dual-energy X-ray absorptiometry; CT: Computerised tomography; SF-36: Short form-36; CLDQ: Chronic liver disease questionnaire; FACIT-F: Functional assessment of chronic illness therapy - fatigue; IBD -DI: Inflammatory bowel disease - disability index; PIS: Patient information sheet; CTCAE: Common terminology criteria for adverse events; SAE: Serious adverse event; CRF: Case report form; UHB: University Hospitals Birmingham.
\end{abstract}

\section{Acknowledgements}

Not applicable.

\section{Study organisation and oversight}

The study will be managed by the Institute of Inflammation and Ageing, the University of Birmingham, and UHBFT. Indemnity will be covered by the NHS and University for all those conducting the study. There will be a multi-disciplinary research team including the Chief and Principal Investigators, clinicians, allied health professionals and scientists.

\section{Authors' contributions}

AD: concept, design, first draft, reviewing/editing manuscript versions and final manuscript. FRW and JIQ: reviewing/editing of manuscript versions and final manuscript. CAG, MJA, AME, JML, LB, AF, KR, GGL reviewing/editing of manuscript versions and final manuscript. SC, SG, PNN, SA: reviewing/editing of final manuscript. All authors read and approved the final manuscript.

\section{Funding}

The study is funded by the National Institute for Health Research Birmingham Biomedical Research Centre at the University Hospitals of Birmingham and the University of Birmingham, UK.
Availability of data and materials

Not applicable.

\section{Declarations}

\section{Ethics approval and consent to participate}

The Health Research Authority and West Midlands Solihull Research Ethics Service Committee Authority (REC reference: 18/WM/0167) approved this study. All participants will provide informed written consent. Potential subjects will be identified by the relevant clinical team and by the lead researcher as detailed in patient selection. This will include a face to face discussion, confirmation of the study details via letter or email, and a follow-up telephone call. All patients will be provided with a patient information sheet (PIS) outlining the purpose of the study. They will receive a follow-up telephone call/ consultation, within 4 weeks after receiving the PIS, where an investigator will introduce and explain the study participation. Formal written consent will be taken at the first visit. The patient will have opportunities to further discuss their participation at their initial visit. The patient will be free to refuse to take part or withdraw from the study at any time and this decision will not affect their care. A copy of the informed consent form will be offered to the patient, and the original placed in the case report file and uploaded on to the hospital electronic patient record.

\section{Consent for publication}

Not applicable.

\section{Competing interests}

The authors declare they have no competing interests.

\section{Author details}

${ }^{1}$ Institute of Inflammation and Ageing, University of Birmingham, Birmingham B15 2TT, UK. ${ }^{2}$ University of Hospitals of Birmingham NHS Trust, Birmingham, UK. ${ }^{3} \mathrm{NIHR}$ Biomedical Research Centre (BRC), University Hospitals Birmingham and University of Birmingham, Birmingham, UK. ${ }^{4}$ School of Sport, Exercise and Rehabilitation Science, University of Birmingham, Birmingham, UK. ${ }^{5}$ MRC-Versus Arthritis Centre for Musculoskeletal Research, University of Birmingham, Birmingham, UK. ${ }^{6}$ Sandwell and West Birmingham NHS Trust, Birmingham, UK. Institute of Metabolism and Systems Research, University of Birmingham, Birmingham, UK.

Received: 18 March 2021 Accepted: 19 November 2021

Published online: 11 December 2021

\section{References}

1. Cruz-Jentoft AJ, Baeyens JP, Bauer JM, Boirie Y, Cederholm T, Landi F, et al. Sarcopenia: European consensus on definition and diagnosis-report of the European Working Group on Sarcopenia in Older People. Age Ageing. 2010;39:412.

2. Cruz-Jentoft AJ, Bahat G, Bauer J, Boirie Y, Bruyère O, Cederholm T, et al. Sarcopenia: revised European consensus on definition and diagnosis. Age Ageing. 2019;48(1):16-31.

3. Velloso CP. Regulation of muscle mass by growth hormone and IGF-I. Br J Pharmacol. 2008;154(3):557-68.

4. Taillandier D, Polge C. Skeletal muscle atrogenes: From rodent models to human pathologies. Biochimie. 2019;166:251-69.

5. Schaap LA, Pluijm SM, Deeg DJ, Visser M. Inflammatory markers and loss of muscle mass (sarcopenia) and strength. Am J Med. 2006;1 19(6):526. e9-17.

6. Morgan SA, Hassan-Smith ZK, Doig CL, Sherlock M, Stewart PM, Lavery GG. Glucocorticoids and 11 $\beta$-HSD1 are major regulators of intramyocelIular protein metabolism. J Endocrinol. 2016;229(3):277-86.

7. Whittemore LA, Song K, Li X, Aghajanian J, Davies M, Girgenrath S, et al. Inhibition of myostatin in adult mice increases skeletal muscle mass and strength. Biochem Biophys Res Commun. 2003;300(4):965-71.

8. Cederholm T, Barazzoni R, Austin P, Ballmer P, Biolo G, Bischoff SC, et al. ESPEN guidelines on definitions and terminology of clinical nutrition. Clin Nutr. 2017;36(1):49-64. 
9. European Association for the Study of the Liver. Electronic address eee, European Association for the Study of the L. EASL Clinical Practice Guidelines on nutrition in chronic liver disease. J Hepatol. 2019;70(1):172-93.

10. Dasarathy S, Merli M. Sarcopenia from mechanism to diagnosis and treatment in liver disease. J Hepatol. 2016;65(6):1232-44.

11. Ebadi M, Bhanji RA, Mazurak VC, Montano-Loza AJ. Sarcopenia in cirrhosis: from pathogenesis to interventions. J Gastroenterol. 2019;54(10):845-59.

12. Hanai T, Shiraki M, Nishimura K, Ohnishi S, Imai K, Suetsugu A, et al. Sarcopenia impairs prognosis of patients with liver cirrhosis. Nutrition. 2015;31(1):193-9.

13. Montano-Loza AJ, Duarte-Rojo A, Meza-Junco J, Baracos VE, Sawyer MB, Pang JXQ, et al. Inclusion of Sarcopenia Within MELD (MELD-Sarcopenia) and the Prediction of Mortality in Patients With Cirrhosis. Clin Transl Gastroenterol. 2015;6(7):e102-e.

14. van Ginneken BTJ, van den Berg-Emons RJG, Kazemier G, Metselaar HJ, Tilanus HW, Stam HJ. Physical fitness, fatigue, and quality of life after liver transplantation. Eur J Appl Physiol. 2007;100(3):345-53.

15. Dhaliwal A, Williams FR, El-sherif O, Armstrong MJ. Sarcopenia in Liver Transplantation: an Update. Curr Hepatol Rep. 2020;19(2):128-37.

16. Kamath PS, Wiesner RH, Malinchoc M, Kremers W, Therneau TM, Kosberg $\mathrm{CL}$, et al. A model to predict survival in patients with end-stage liver disease. Hepatology (Baltimore, Md). 2001;33(2):464-70.

17. Tsien C, Davuluri G, Singh D, Allawy A, Ten Have GAM, Thapaliya S, et al. Metabolic and molecular responses to leucine-enriched branched chain amino acid supplementation in the skeletal muscle of alcoholic cirrhosis. Hepatology (Baltimore, Md). 2015;61 (6):2018-29.

18. Hassan-Smith ZK, Morgan SA, Sherlock M, Hughes B, Taylor AE, Lavery GG, et al. Gender-Specific Differences in Skeletal Muscle 11 beta-HSD1 Expression Across Healthy Aging. J Clin Endocrinol Metab. 2015;100(7):2673-81.

19. Scaldaferri F, Pizzoferrato M, Lopetuso LR, Musca T, Ingravalle F, Sicignano LL, et al. Nutrition and IBD: Malnutrition and/or Sarcopenia? A Practical Guide. Gastroenterol Res Pract. 2017;2017:8646495.

20. Ryan E, McNicholas D, Creavin B, Kelly ME, Walsh T, Beddy D. Sarcopenia and Inflammatory Bowel Disease: A Systematic Review. Inflamm Bowel Dis. 2018;25(1):67-73.

21. Gower-Rousseau C, Sarter H, Savoye G, Tavernier N, Fumery M, Sandborn WJ, et al. Validation of the Inflammatory Bowel Disease Disability Index in a population-based cohort. Gut. 2017;66(4):588-96.

22. Grimstad T, Norheim KB, Isaksen K, Leitao K, Hetta AK, Carlsen A, et al. Fatique in Newly Diagnosed Inflammatory Bowel Disease. J Crohns Colitis. 2015;9(9):725-30.

23. Pizzoferrato M, de Sire R, Ingravalle F, Mentella MC, Petito V, Martone AM, et al. Characterization of Sarcopenia in an IBD Population Attending an Italian Gastroenterology Tertiary Center. Nutrients. 2019;1 (10):2281.

24. Dhaliwal A, Quinlan JI, Overthrow K, Greig C, Lord JM, Armstrong MJ, et al. Sarcopenia in Inflammatory Bowel Disease: A Narrative Overview. Nutrients. 2021;13(2):656.

25. Bamba S, Sasaki M, Takaoka A, Takahashi K, Imaeda H, Nishida A, et al. Sarcopenia is a predictive factor for intestinal resection in admitted patients with Crohn's disease. PLoS One. 2017;12(6):e0180036-e.

26. van Langenberg DR, Gatta PD, Hill B, Zacharewicz E, Gibson PR, Russel AP. Delving into disability in Crohn's disease: Dysregulation of molecular

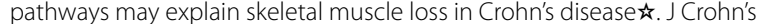
Colitis. 2014;8(7):626-34.

27. Subramaniam K, Fallon K, Ruut T, Lane D, McKay R, Shadbolt B, et al. Infliximab reverses inflammatory muscle wasting (sarcopenia) in Crohn's disease. Aliment Pharmacol Ther. 2015;41(5):419-28.

28. Malm K, Bergman S, Andersson MLE, Bremander A, Larsson I. Quality of life in patients with established rheumatoid arthritis: A phenomenographic study. SAGE Open Med. 2017;5:2050312117713647.

29. Katz P. Causes and consequences of fatigue in rheumatoid arthritis. Curr Opin Rheumatol. 2017;29(3):269-76.

30. Guo Q, Wang Y, Xu D, Nossent J, Pavlos NJ, Xu J. Rheumatoid arthritis: pathological mechanisms and modern pharmacologic therapies. Bone Res. 2018;6:15.

31. Chimenti MS, Triggianese P, Conigliaro P, Candi E, Melino G, Perricone R. The interplay between inflammation and metabolism in rheumatoid arthritis. Cell Death Dis. 2015;6(9):e1887-e.

32. Morgan SA, McCabe EL, Gathercole LL, Hassan-Smith ZK, Larner DP Bujalska IJ, et al. 11ß-HSD1 is the major regulator of the tissue-specific effects of circulating glucocorticoid excess. Proc Natl Acad Sci U S A. 2014;111(24):E2482-E91.

33. Masuko K. Rheumatoid Cachexia Revisited: A Metabolic Co-Morbidity in Rheumatoid Arthritis. Front Nutr. 2014;1:20. https://doi.org/10.3389/ fnut.2014.00020.

34. Baillet A, Vaillant M, Guinot M, Juvin R, Gaudin P. Efficacy of resistance exercises in rheumatoid arthritis: meta-analysis of randomized controlled trials. Rheumatology. 2011;51(3):519-27.

35. Khoja SS, Almeida GJ, Chester Wasko M, Terhorst L, Piva SR. Association of Light-Intensity Physical Activity With Lower Cardiovascular Disease Risk Burden in Rheumatoid Arthritis. Arthritis Care Res (Hoboken). 2016;68(4):424-31.

36. Tournadre A, Vial G, Capel F, Soubrier M, Boirie Y. Sarcopenia. Joint Bone Spine. 2019;86(3):309-14.

37. Lemmey AB, Marcora SM, Chester K, Wilson S, Casanova F, Maddison PJ. Effects of high-intensity resistance training in patients with rheumatoid arthritis: A randomized controlled trial. Arthritis Care Res (Hoboken). 2009:61(12):1726-34

38. Banugo P, Amoako D. Prehabilitation. BJA Educ. 2017;17(12):401-5.

39. Duarte-Rojo A, Ruiz-Margáin A, Montaño-Loza AJ, Macías-Rodríguez RU, Ferrando A, Kim WR. Exercise and physical activity for patients with end-stage liver disease: Improving functional status and sarcopenia while on the transplant waiting list. Liver Transplant. 2018;24(1):122-39.

40. Williams AM, Waits S, Englesbe MJ. The Importance of Prehabilitation in Liver Transplantation. Curr Transplant Rep. 2015;2(4):312-5.

41. Lamb CA, Kennedy NA, Raine T, Hendy PA, Smith PJ, Limdi JK, et al. British Society of Gastroenterology consensus guidelines on the management of inflammatory bowel disease in adults. Gut. 2019;68(Suppl 3):s1-s106.

42. Emery P, Pope JE, Kruger K, Lippe R, DeMasi R, Lula S, et al. Efficacy of Monotherapy with Biologics and JAK Inhibitors for the Treatment of Rheumatoid Arthritis: A Systematic Review. Adv Ther. 2018;35(10):1535-63.

43. Curtis JR, Singh JA. Use of biologics in rheumatoid arthritis: current and emerging paradigms of care. Clin Ther. 2011;33(6):679-707.

44. NICE. Drug treament for rheumatoid arthritis National Institute for Health and Care Excellence. 2021.

45. Neurath MF, Travis SP. Mucosal healing in inflammatory bowel diseases: a systematic review. Gut. 2012;61(11):1619-35.

46. Roubenoff R, Parise $H$, Payette HA, Abad LW, D'Agostino R, Jacques PF, et al. Cytokines, insulin-like growth factor 1 , sarcopenia, and mortality in very old community-dwelling men and women: the Framingham Heart Study. Am J Med. 2003;115(6):429-35.

47. Wilson D, Jackson T, Sapey E, Lord JM. Frailty and sarcopenia: The potential role of an aged immune system. Ageing Res Rev. 2017:36:1-10.

48. Naranjo JD, Dziki JL, Badylak SF. Regenerative Medicine Approaches for Age-Related Muscle Loss and Sarcopenia: A Mini-Review. Gerontology. 2017:63(6):580-9.

49. Long CL, Dillard DR, Bodzin JH, Geiger JW, Blakemore WS. Validity of 3-methylhistidine excretion as an indicator of skeletal muscle protein breakdown in humans. Metabolism. 1988;37(9):844-9.

50. Lai JC, Dodge JL, Sen S, Covinsky K, Feng S. Functional decline in patients with cirrhosis awaiting liver transplantation: Results from the functional assessment in liver transplantation (FrAlLT) study. Hepatology (Baltimore, Md). 2016;63(2):574-80.

51. Guralnik JM, Ferrucci L, Pieper CF, Leveille SG, Markides KS, Ostir GV, et al. Lower extremity function and subsequent disability: consistency across studies, predictive models, and value of gait speed alone compared with the short physical performance battery. J Gerontol A Biol Sci Med Sci. 2000;55(4):M221-31.

52. Aamann L, Dam G, Borre M, Drljevic-Nielsen A, Overgaard K, Andersen H, et al. Resistance Training Increases Muscle Strength and Muscle Size in Patients With Liver Cirrhosis. Clin Gastroenterol Hepatol. 2020;18(5):117987.e6. https://doi.org/10.1016/j.cgh.2019.07.058. Epub 2019 Aug 5.

53. Orr JG, Homer T, Ternent L, Newton J, McNeil CJ, Hudson M, et al. Health related quality of life in people with advanced chronic liver disease. J Hepatol. 2014;61(5):1158-65.

54. Janani K, Jain M, Vargese J, Srinivasan V, Harika K, Michael T, et al. Healthrelated quality of life in liver cirrhosis patients using SF-36 and CLDQ questionnaires. Clin Exp Hepatol. 2018;4(4):232-9. 
55. Hewlett S, Dures E, Almeida C. Measures of fatigue: Bristol Rheumatoid Arthritis Fatigue Multi-Dimensional Questionnaire (BRAF MDQ), Bristol Rheumatoid Arthritis Fatigue Numerical Rating Scales (BRAF NRS) for severity, effect, and coping, Chalder Fatigue Questionnaire (CFQ), Checklist Individual Strength (CIS20R and CIS8R), Fatigue Severity Scale (FSS), Functional Assessment Chronic Illness Therapy (Fatigue) (FACIT-F), MultiDimensional Assessment of Fatigue (MAF), Multi-Dimensional Fatigue Inventory (MFI), Pediatric Quality Of Life (PedsQL) Multi-Dimensional Fatigue Scale, Profile of Fatigue (ProF), Short Form 36 Vitality Subscale (SF-36 VT), and Visual Analog Scales (VAS). Arthritis Care Res (Hoboken). 2011;63(Suppl 11):S263-S86.

56. Peolsson A, Hedlund R, Oberg B. Intra- and inter-tester reliability and reference values for hand strength. J Rehabil Med. 2001;33(1):36-41.

57. Clarys JP, Marfell-Jones MJ. Anthropometric prediction of component tissue masses in the minor limb segments of the human body. Hum Biol. 1986;58(5):761-9.

58. Clarys JP, Martin AD, Drinkwater DT, Marfell-Jones MJ. The skinfold: myth and reality. J Sports Sci. 1987;5(1):3-33.

59. Hume P, Marfell-Jones M. The importance of accurate site location for skinfold measurement. J Sports Sci. 2008;26(12):1333-40.

60. Gleeson NP, Mercer TH. The utility of isokinetic dynamometry in the assessment of human muscle function. Sports Med. 1996;21(1):18-34

61. Tsekoura M, Billis E, Tsepis E, Dimitriadis Z, Matzaroglou C, Tyllianakis M, et al. The Effects of Group and Home-Based Exercise Programs in Elderly with Sarcopenia: A Randomized Controlled Trial. J Clin Med. 2018;7(12).

62. Narici MV, Roi GS, Landoni L, Minetti AE, Cerretelli P. Changes in force, cross-sectional area and neural activation during strength training and detraining of the human quadriceps. Eur J Appl Physiol Occup Physiol. 1989;59(4):310-9.

63. Akagi R, Iwanuma S, Fukuoka M, Kanehisa H, Fukunaga T, Kawakami Y. Methodological issues related to thickness-based muscle size evaluation. J Physiol Anthropol. 2011;30(4):169-74.

64. Takai Y, Ohta M, Akagi R, Kato E, Wakahara T, Kawakami Y, et al. Applicability of ultrasound muscle thickness measurements for predicting fat-free mass in elderly population. J Nutr Health Aging. 2014;18(6):579-85.

65. Franchi MV, Atherton PJ, Reeves ND, Fluck M, Williams J, Mitchell WK, et al. Architectural, functional and molecular responses to concentric and eccentric loading in human skeletal muscle. Acta Physiol (Oxf). 2014;210(3):642-54.

66. Carey EJ, Lai JC, Wang CW, Dasarathy S, Lobach I, Montano-Loza AJ, et al. A multicenter study to define sarcopenia in patients with end-stage liver disease. Liver Transpl. 2017;23(5):625-33.

67. Kang SH, Kim MY, Baik SK. The Impact of Sarcopenia and Its Rate of Change on Prognostic Value of Liver Cirrhosis. J Korean Med Sci. 2018;33(50):e334.

68. Carey EJ, Lai JC, Sonnenday C, Tapper EB, Tandon P, Duarte-Rojo A, et al. A North American Expert Opinion Statement on Sarcopenia in Liver Transplantation. Hepatology. 2019.

69. Lai JC, Covinsky KE, McCulloch CE, Feng S. The Liver Frailty Index Improves Mortality Prediction of the Subjective Clinician Assessment in Patients With Cirrhosis. Am J Gastroenterol. 2018;113(2):235-42.

70. Montano-Loza AJ, Angulo P, Meza-Junco J, Prado CM, Sawyer MB, Beau-

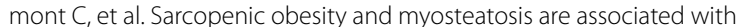
higher mortality in patients with cirrhosis. J Cachexia Sarcopenia Muscle. 2016;7(2):126-35.

71. Zamboni M, Gattazzo S, Rossi AP. Myosteatosis: a relevant, yet poorly explored element of sarcopenia. Eur Geriatr Med. 2019;10(1):5-6.

72. Boutin RD, Yao L, Canter RJ, Lenchik L. Sarcopenia: Current Concepts and Imaging Implications. Am J Roentgenol. 2015;205(3):W255-W66.

73. Cruz-Jentoft AJ, Sayer AA. Sarcopenia. Lancet (London, England). 2019;393(10191):2636-46.

74. Berzigotti A, Saran U, Dufour JF. Physical activity and liver diseases. Hepatology. 2016;63(3):1026-40.

75. Tandon P, Ney M, Irwin I, Ma MM, Gramlich L, Bain VG, et al. Severe muscle depletion in patients on the liver transplant wait list: its prevalence and independent prognostic value. Liver Transpl. 2012;18(10):1209-16.

76. Hu X, Jiang J, Wang H, Zhang L, Dong B, Yang M. Association between sleep duration and sarcopenia among community-dwelling older adults: A cross-sectional study. Medicine (Baltimore). 2017;96(10):e6268-e.
77. Nishikawa H, Enomoto H, Yoh K, Iwata Y, Sakai Y, Kishino K, et al. Effect of Sarcopenia on Sleep Disturbance in Patients with Chronic Liver Diseases. J Clin Med. 2018:8(1):16.

78. Patidar KR, Bajaj JS. Covert and Overt Hepatic Encephalopathy: Diagnosis and Management. Clin Gastroenterol Hepatol. 2015;13(12):2048-61.

79. Dasarathy S, McCullough AJ, Muc S, Schneyer A, Bennett CD, Dodig M, et al. Sarcopenia associated with portosystemic shunting is reversed by follistatin. J Hepatol. 2011;54(5):915-21.

80. Shanely RA, Zwetsloot KA, Triplett NT, Meaney MP, Farris GE, Nieman DC Human skeletal muscle biopsy procedures using the modified Bergström technique. J Vis Exp. 2014;91:51812.

81. Kurup AN, Lekah A, Reardon ST, Schmit GD, McDonald JS, Carter RE, et al. Bleeding Rate for Ultrasound-Guided Paracentesis in Thrombocytopenic Patients. J Ultrasound Med. 2015:34(10):1833-8.

82. Runyon BA. Management of adult patients with ascites due to cirrhosis: an update. Hepatology. 2009;49(6):2087-107.

83. Veitch AM, Vanbiervliet G, Gershlick AH, Boustiere C, Baglin TP, Smith LA, et al. Endoscopy in patients on antiplatelet or anticoagulant therapy, including direct oral anticoagulants: British Society of Gastroenterology (BSG) and European Society of Gastrointestinal Endoscopy (ESGE) guidelines. Endoscopy. 2016;48(4):c1.

84. Dhatariya K, Levy N, Kilvert A, Watson B, Cousins D, Flanagan D, et al. NHS Diabetes guideline for the perioperative management of the adult patient with diabetes. Diabetic Med. 2012;29(4):420-33.

\section{Publisher's Note}

Springer Nature remains neutral with regard to jurisdictional claims in published maps and institutional affiliations.

Ready to submit your research? Choose BMC and benefit from

- fast, convenient online submission

- thorough peer review by experienced researchers in your field

- rapid publication on acceptance

- support for research data, including large and complex data types

- gold Open Access which fosters wider collaboration and increased citations

- maximum visibility for your research: over $100 \mathrm{M}$ website views per year

At BMC, research is always in progress.

Learn more biomedcentral.com/submissions 